\title{
Abdominal cocoon secondary to disseminated tuberculosis
}

\author{
Radha Puppala, ${ }^{1}$ Smiti Sripathi, ${ }^{1}$ Rajagopal Kadavigere, ${ }^{1}$ Prakashini Koteshwar, ${ }^{1}$ \\ Jyoti Singh 2
}

${ }^{1}$ Department of

Radiodiagnosis, Kasturba

Medical College, Manipal,

Karnataka, India

${ }^{2}$ Malathi Manipal Hospital,

Bangalore, Karnataka, India

Correspondence to

Dr Rajagopal Kadavigere, rajagopalkv@yahoo.co.in

Accepted 15 August 2014

\section{SUMMARY}

Abdominal cocoon, also known as sclerosing encapsulating peritonitis, represents a rare entity where a variable length of the small bowel is enveloped by a fibrocollagenous membrane giving the appearance of a cocoon. It may be asymptomatic and is often diagnosed incidentally at laparotomy. We present a rare case of abdominal cocoon due to abdominal tuberculosis.

\section{BACKGROUND}

The most common cause of a cocoon is nontubercular or chronic inflammation of the peritoneal cavity, such as long-standing ascites due to cirrhosis. In our case, tuberculosis was the confirmed cause for the formation of the cocoon.

\section{CASE PRESENTATION}

A 55-year-old man presented with abdominal pain and distension of 1 month duration. He also had a history of insidious onset of episodic fever with myalgia, pedal oedema, easy fatigability, loss of weight and appetite, and off and on abdominal pain for the past 1 year. The patient had chronic liver disease and was on treatment for it. On general examination, he was emaciated, had pallor and bilateral pitting pedal oedema along with testicular atrophy. Per abdominal examination revealed ascites with engorged abdominal veins and nontender hepatomegaly. Liver function tests revealed isolated elevation of alkaline phosphatase levels.

Ultrasound of the abdomen showed coarse echotexture of liver and ascites. The small bowel loops were seen in the central abdomen and showed normal peristaltic activity; however, there was no dilation of the small bowel loops. Mild left-sided pleural effusion was seen.

Contrast-enhanced CT of the abdomen showed small bowel loops clumped together in the central abdomen encased in a sac-like structure with surrounding ascites and enhanced and thickened peritoneum (figure 1). There was left-sided pleural effusion with underlying subsegmental collapse of the lung.

The patient underwent laparoscopy and biopsy was taken from the peritoneal nodules. Histopathology from the peritoneal nodules showed hyperplastic mesothelial cells with fibrin exudate and overlying granulomas composed of Langhan's and epithelioid giant cells, lymphocytes and plasma cells with no evidence of caseation. Biopsy was also taken from multiple adhesions along the small bowel loops, which was found to be composed of fibrin bands with neutrophils on histopathological examination. A diagnosis of granulomatous peritonitis due to tuberculosis was made. Subsequently, the patient was started on antitubercular treatment along with steroids. During the course of his stay in the hospital, the patient had persistent hypotension, which required ionotropic support. This was attributed to adrenal insufficiency secondary to disseminated tuberculosis.

The patient was discharged on stabilisation of blood pressure and was followed up on outpatient basis for 2 years. The patient demonstrated significant weight gain, had an improved sense of wellbeing, with decrease in abdominal discomfort and there were no further episodes of fever. Ultrasound of abdomen performed on follow-up was normal.

\section{INVESTIGATIONS}

- Liver function tests revealed isolated elevation of alkaline phosphatase levels.

- Ultrasound and contrast-enhanced CT abdomen.

- Diagnostic laparoscopy and biopsy from peritoneal nodules and adhesions along the small bowel loops.

\section{DIFFERENTIAL DIAGNOSIS}

- Internal hernia

- Closed loop obstruction

\section{TREATMENT}

Conservative management with antitubercular medications.

\section{OUTCOME AND FOLLOW-UP}

The patient was discharged on stabilisation of blood pressure and was followed up on outpatient basis for 2 years. The patient demonstrated significant weight gain, had an improved sense of wellbeing, with decrease in abdominal discomfort and there were no further episodes of fever. Ultrasound of abdomen performed on follow-up was normal.

\section{DISCUSSION}

Abdominal cocoon, or 'peritonitis chronic fibrosa incapsulata', is an extremely rare entity first described in 1978 by Foo et al ${ }^{1}$ whose aetiology, pathogenesis and clinical presentations are still obscure.

Histologically, the peritoneum shows a proliferation of fibroconnective tissue, inflammatory infiltrates and dilated lymphatics, with no evidence of foreign body granulomas, giant cells or birefringent material. $^{2-4}$ 'Sclerosing' refers to the progressive 

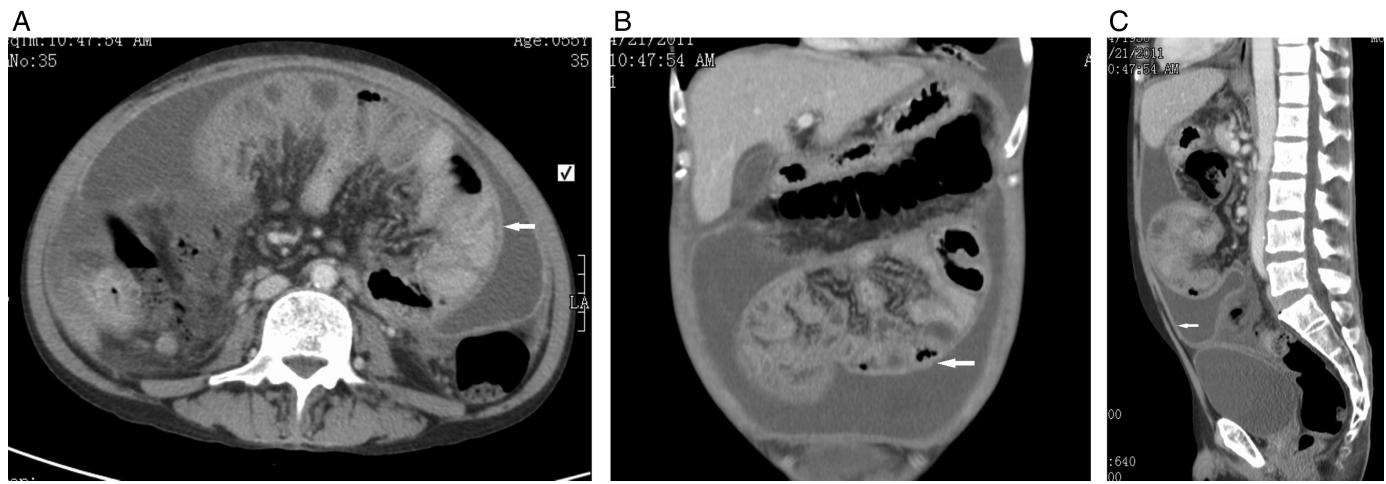

Figure 1 Axial (A) and coronal (B) contrast-enhanced CT sections of the abdomen showing clumped small bowel loops in the central abdomen encased in a sac-like structure with surrounding ascites, and enhanced and thickened peritoneum (C).

formation of sheets of dense collagenous tissue; 'encapsulating' describes the sheath of new fibrous tissue that covers and constricts the small bowel restricting its motility; and 'peritonitis' implies an ongoing inflammatory process and presence of a mononuclear inflammatory infiltrate within the new fibrosing tissue.

Two forms of sclerosing encapsulating peritonitis (SEP) have been described in the literature based on aetiology. The first form is the idiopathic or classic form of SEP. ${ }^{1}$ The basic pathogenesis behind development of the idiopathic form of SEP is developmental abnormality, as the entity is frequently associated with other findings such as greater omentum hypoplasia and mesenteric vessel malformation. ${ }^{5}$ The second form is associated with previous surgeries, viral infections, retrograde menstruation in adolescent girls, recurrent peritonitis, chronic ambulatory peritoneal dialysis, practolol ( $\beta$-blocker) intake, ventriculoperitoneal shunts, sarcoidosis and cirrhotics treated with peritoneovenous shunts. ${ }^{1}{ }^{6-9}$ Another extremely rare cause of abdominal cocoon is tuberculosis, with very few cases reported so far. $^{10}$

Abdominal cocoon can also be classified based on the organs found encapsulated at surgery. The entity is categorised into three types according to the extent of fibrocollagenous encapsulating membrane where: (1) membrane surrounds a few small bowel loops; (2) the whole of the bowel is encapsulated by the membrane; and (3) the bowel and other organs (eg, appendix, caecum, ascending colon, ovary, etc) are encapsulated by the membrane. ${ }^{5} 11$

Rarely, the cocoon may involve other organs such as large bowel, liver and stomach. ${ }^{5}$ Patients who are usually asymptomatic may, however, rarely present with clinical features of acute, subacute and recurrent intestinal obstruction, malnutrition, weight loss, abdominal distension or mass per abdomen. ${ }^{10} 12$

Diagnosis of abdominal cocoon still remains a challenge due to non-specific symptoms. Plain radiograph of the abdomen has limited diagnostic utility except in conjunction with acute/recurrent/subacute bowel obstruction, where transiently dilated bowel loops are seen in the centre of the abdomen. ${ }^{1}$

Ultrasound of the abdomen is used as the initial imaging modality for evaluation, although CT and MRI form the diagnostic modalities of choice. ${ }^{12}$ Ultrasound findings include large echogenic mass associated with small amounts of localised fluid collection or ascites. At times bowel wall thickening and oedema can be noted. ${ }^{6}$ When there is bowel obstruction secondary to tethering of bowel loops, the loops appear dilated and show sluggish or reverse peristalsis. Demonstration of the encapsulating membrane or the fibrous adhesions is difficult and these are rarely appreciated on ultrasound.
The ability of cross-sectional imaging modalities to depict clustered small bowel loops encapsulated by a thin sac is considered the diagnostic finding as described by Wig and Gupta ${ }^{12}$ and the presence of gross ascites with small-bowel intestine loops placed together in a single area within the peritoneal cavity is considered typical of abdominal cocoon on an abdominal CT as described by Maguire et al. ${ }^{13}$

Other associated findings are localised fluid collection or ascites, enhancing thickened peritoneum, peritoneal calcifications and nodules. Those cases that present with intestinal obstruction show clumped, dilated bowel loops due to closed loop obstruction. ${ }^{6} 7$

Barium studies have also been described by Sieck et al, ${ }^{14}$ which showed fixed clustered small bowel loops in a concertina/ cauliflower pattern with increased transit time in a few cases.

In our case, ultrasound of the abdomen showed clumped bowel loops in the umbilical region with normal peristalsis and para-aortic lymphadenopathy. There were no features of small bowel obstruction, hence surgery was not considered, and laparoscopic biopsy was also performed to confirm the diagnosis.

\section{Learning point}

Abdominal cocoon is a rare condition that requires a high index of clinical suspicion and diagnosis supported by imaging findings; however, explorative laparotomy still holds as the gold standard for diagnosis.

Competing interests None.

Patient consent Obtained.

Provenance and peer review Not commissioned; externally peer reviewed.

\section{REFERENCES}

1 Foo KT, Ng KC, Rauff A, et al. Unusual small intestinal obstruction in adolescent girls: the abdominal cocoon. Br J Surg 1978;65:427-30.

2 Clatworthy MR, Williams P, Watson CJ, et al. The calcified abdominal cocoon. Lancet 2008;371:1452.

3 Honda K, Oda H. Pathology of encapsulating peritoneal sclerosis. Perit Dial Int 2005;25:S19-29.

4 Okada K, Onishi Y, Oinuma T, et al. Sclerosing encapsulating peritonitis: regional changes of peritoneum. Nephron 2002;92:481-3.

5 Tannoury JN, Abboud BN. Idiopathic sclerosing encapsulating peritonitis: abdominal cocoon. World J Gastroenterol 2012;18:1999-2004. 
6 Hur J, Kim KW, Park MS, et al. Abdominal cocoon: preoperative diagnostic clues from radiologic imaging with pathologic correlation. AJR Am J Roentgenol 2004;182:639-41.

7 Krestin GP, Kacl G, Hauser M, et al. Imaging diagnosis of sclerosing peritonitis and relation of radiologic signs to the extent of the disease. Abdom Imaging 1995;20:414-20.

8 Lalloo S, Krishna D, Maharajah J. Abdominal cocoon associated with tuberculous pelvic inflammatory disease. Br J Radiol 2002;75:174-6.

9 Hollman AS, McMillan MA, Briggs JD, et al. Ultrasound changes in sclerosing peritonitis following continuous ambulatory peritoneal dialysis. Clin Radiol 1991;43:176-9.
10 Kaushik R, Punia RP, Mohan $\mathrm{H}$, et al. Tuberculous abdominal cocoon-a report of 6 cases and review of the literature. World J Emerg Surg 2006;1:18.

11 Wei B, Wei HB, Guo WP, et al. Diagnosis and treatment of abdominal cocoon: a report of 24 cases. Am J Surg 2009;198:348-53.

12 Wig JD, Gupta SK. Computed tomography in abdominal cocoon. J Clin Gastroenterol 1998;26:156-15.

13 Maguire D, Srinivasan $P, O^{\prime}$ Grady J, et al. Sclerosing encapsulating peritonitis after orthotopic liver transplantation. Am J Surg 2001;182:151-4.

14 Sieck JO, Cowgill R, Larkworthy W. Peritoneal encapsulation and abdominal cocoon: case reports and a review of the literature. Gastroenterology 1983;84:1597-601.

Copyright 2014 BMJ Publishing Group. All rights reserved. For permission to reuse any of this content visit

http://group.bmj.com/group/rights-licensing/permissions.

BMJ Case Report Fellows may re-use this article for personal use and teaching without any further permission.

Become a Fellow of BMJ Case Reports today and you can:

- Submit as many cases as you like

- Enjoy fast sympathetic peer review and rapid publication of accepted articles

- Access all the published articles

- Re-use any of the published material for personal use and teaching without further permission

For information on Institutional Fellowships contact consortiasales@bmjgroup.com

Visit casereports.bmj.com for more articles like this and to become a Fellow 